\title{
First versus Second Generation Electronic Cigarettes: Predictors of Choice and Effects on Urge to Smoke and Withdrawal Symptoms
}

\author{
Running head: First vs. Second Generation E-Cigarettes
}

Lynne Dawkins, Catherine Kimber, Yasothani Puwanesarasa and Kirstie Soar

\author{
School of Psychology \\ University of East London \\ Water Lane \\ Stratford \\ London, E15 4LZ
}

Corresponding author: Lynne Dawkins, e-mail: L.E.Dawkins@uel.ac.uk; tel.: + 44 (0) 208332 4421; fax: Fax: +44 (0)20 82234937

\section{Word Count: 3644}

\section{Declarations of Interest:}

Lynne Dawkins has previously conducted research for electronic cigarette companies for which the University of East London (UEL) has received funds. She has no financial conflict of interest associated with her involvement with electronic cigarette companies and no conflict of interest with the Tobacco or Pharmaceutical Industry. No funds were received to support this study. All other authors declare no conflict of interest. 


\section{ABSTRACT}

Aims: To 1) estimate predictors of first vs. second generation electronic cigarette (e-cigarette) choice; 2) determine whether a second generation device was i) superior for reducing urge to smoke and withdrawal symptoms (WS) and ii) associated with enhanced positive subjective effects. Design: Mixed effects experimental design. Phase 1: reason for e-cigarette choice was assessed via questionnaire. Phase 2: participants were randomly allocated to first or second generation e-cigarette condition. Urge to smoke and WS were measured before, and 10mins after, taking 10 e-cigarette puffs. Setting: University of East London, UK. Participants: 97 smokers (mean age 26; SD 8.7; 54\% female) Measurements: Single item urge to smoke scale to assess craving; Mood and Physical Symptoms Scale (MPSS) to assess WS. Subjective effects included: satisfaction, hit, 'felt like smoking' and 'would use to stop smoking' (Yes vs. No response). Findings: Equal numbers chose each device but none of the predictor variables (gender, age, tobacco dependence, previous e-cigarette use) accounted for choice. Only baseline urge to smoke/WS predicted urge to smoke/WS 10 minutes after use $(B=0.38 ; P<0.001$ and $B=0.53 ; P<0.001)$. E-cigarette device was not a significant predictor. Those using the second generation device were more likely to report satisfaction and use in a quit attempt $\left(\chi^{2}=12.10, P=0.001\right.$ and $\left.\chi^{2}=5.53, P=0.02\right)$. Conclusions: First and second generation e-cigarettes appear to be similarly effective in reducing urge to smoke and WS during abstinence but second generation devices appear to be more satisfying to users. 


\section{INTRODUCTION}

Electronic cigarettes (e-cigarettes; also known as electronic nicotine delivery systems [ENDS] or personal vaporisers) are battery-powered devices that deliver nicotine in an aerosol of inhaled propylene glycol or glycerol. Since e-cigarettes heat rather than burn, the production of toxins and carcinogens is far lower than from conventional tobacco smoking [1-3]. Following introduction into Europe and the US in 2006, e-cigarette use has become increasingly popular with sales in the US doubling each year from $\$ 20 m$ in 2008 to $\$ 750 m$ - $\$ 1$ bn in 2013. In March 2014 Wells Fargo Securities estimated the total size of the US retail market at $\$ 2 \mathrm{bn}$ [4]. Current use by smokers in the UK increased from 3\% in 2010 to $19 \%$ in 2014 [5] and similarly, in the US, from 3.3\% in 2010 to $6.2 \%$ in 2011 [6]. Ecigarettes, however, are the subject of furious public health debate. Some advocate them as one of the greatest public health breakthroughs in tobacco control history with potential to save millions of smoking-related deaths [7,8]; opponents fear they could re-normalise smoking and appeal to nonsmokers, acting as a gateway to cigarette smoking $[9,10]$.

All e-cigarettes comprise a lithium battery, a cartridge containing the e-liquid, and an atomiser which heats the e-liquid to create the aerosol. There is marked variability however, in visual appearance; some, commonly referred to as first generation devices, resemble tobacco cigarettes (cigalikes). These comprise low-capacity disposable or re-chargeable batteries and combined cartridges and atomisers (cartomisers). Second generation devices resemble pens or gadgets and use larger batteries and fluid filled reservoirs (clearomisers or tanks), filled from bottles of e-liquid. Third generation devices bear little resemblance to cigarettes, use larger-capacity batteries, replacement heating coils and wicks for atomizers, and adjustable and programmable power delivery. Whilst early studies reported very little nicotine delivery from e-cigarettes [11,12], more recently, studies in experienced users have found measureable nicotine delivery (comparable to nicotine replacement therapy; NRT) $[13,14]$ especially with newer generation devices [15]. 
E-cigarette use (often referred to as vaping) resembles the act of smoking: the user holds the device and draws on it like a cigarette; the aerosol produced resembles smoke and is drawn into the lungs and exhaled like smoke; tobacco (or menthol) flavouring mimics the taste of tobacco smoke and first generation devices resemble cigarettes exactly. Although nicotine is clearly a critical component of smoking addiction, a growing body of evidence points to the importance of non-nicotine factors. For example, smokers enjoy the sensory and tactile components of smoking, including the hand-mouth activity, taste, smell and sensations in the respiratory tract [16]. Denicotinised cigarette smoking can alleviate nicotine withdrawal symptoms (WS) and craving $[17,18]$ and is preferred over receiving nicotine intravenously [19]. Such sensorimotor cues likely act as conditioned reinforcers by virtue of their pairing with the primary reinforcer, nicotine, thus contributing to maintenance of tobacco addiction. Replacing these cues as well as delivering nicotine may contribute to the popularity of ecigarettes among smokers [20]. Indeed, pilot work in our laboratory shows that in e-cigarette-naive smokers, visual similarity to cigarettes is important for craving reduction and symptom relief, and cigalike placebo devices can also be effective [21].

Mimicking the visual and sensorimotor characteristics of smoking is likely to be more important for some smokers than others. For example, it is possible that more dependent smokers or those with a longer smoking history might be more responsive to cigarette-like cues, given the length of the conditioning process. Gender differences are also documented; compared to men, the smoking behaviour of women may be more influenced by non-nicotine stimuli associated with smoking such as the look, touch and feel of cigarettes [22]. In relation to e-cigarette use, placebos have been shown to be as effective as nicotine containing devices for reducing craving and nicotine-related WS in women but not in men [21]. Whether it is important for an e-cigarette to resemble a conventional cigarette, and for whom, is important if the widespread use of e-cigarettes, especially cigalikes (first generation devices) undermines tobacco control efforts and makes smoking socially acceptable. Nevertheless, whilst first generation cigalike devices may be appealing to smokers, especially those 
with little previous experience of e-cigarettes (as found in our pilot work), regular e-cigarette users more commonly report using second and third generation devices $[23,24]$. Preliminary evidence based on retrospective reporting suggest that such devices may be superior for smoking cessation [25] and in experienced exclusive e-cigarette users, better than first generation devices for blood nicotine delivery and alleviation of craving [15].

The aims of the current study were: 1 ) to determine whether gender, cigarette dependence, previous e-cigarette use and age predict e-cigarette choice (first generation cigalike vs. a second generation device) in e-cigarette-inexperienced smokers (phase 1) and, 2) to determine whether a second generation device is superior to a first generation device for i) reducing urge to smoke and nicotinerelated WS and ii) enhancing subjective effects (e.g. hit and satisfaction; phase 2). In abstinent smokers (between 1 and 12 hours), craving and WS reduction have previously been reported following use of both first $[11,12,21]$ and second [26] generation devices, but none have directly compared the two in non e-cigarette-using smokers. Determining for whom cigarette-like appearance might be important and assessing their appeal and effectiveness against second generation cigarette-dissimilar devices may have clinical utility as well as marketing and regulatory implications.

\section{METHOD}

\section{Participants}

One hundred participants were recruited over a three month period. In the absence of previous work examining predictors of e-cigarette choice, we used Green's (1991) rule of thumb (cited in Tabachnick \& Fidell, 2007) [27] to determine the number of participants required for phase $1(N \geq 50+8(\mathrm{~m})$ where $m$ is the number of IVs) assuming a medium-sized relationship between the IVs and DVs, $\alpha=0.05$ and four predictor variables. $50+(8)(4)=82$ which we rounded up to 100 to allow for drop out. For phase 2 , this sample size provides in excess of $99 \%$ power to detect an effect of e-cigarette device ( $1^{\text {st }}$ 
vs. $2^{\text {nd }}$ generation) on craving at $\alpha=0.05$ based on the work of Farsalinos and colleagues [15] who observed a very large effect size (Cohen's $d=1.26$ ) when comparing craving to vape between a first and a new generation device.

Participants responded to advertisements (online and on campus) at the University of East London by e-mailing or telephoning the researcher. All were daily smokers (smoke $>1$ cigarette a day for at least the last year), abstinent from smoking/nicotine use for at least one hour (consistent with [21]) and were not currently using e-cigarettes. Exclusion criteria included pregnancy/suspected pregnancy, breast-feeding, serious medical condition (i.e. heart disease or recent stroke or neurological diagnosis). Two participants who failed to comply with the study puffing procedures (ten threesecond puffs with a 30 second inter-puff interval) and one who was a non-daily smoker were withdrawn. Thus, all analyses were conducted on ninety-seven participants, 53 (54\%) female, 79 (81\%) students, aged between 18 and 60 years old $(M=25.78, S D=8.69)$. Fifty four participants (56\%) had previously tried an e-cigarette (mean 15 times, SD: 36; range 1 - 180 times) with $82 \%$ having used on fewer than 5 occasions. The ethnic composition of the sample was: White (60\%), Black African and Caribbean (11\%), Asian (10\%), Mixed Race (8\%), Chinese (1\%) and Other (9\%).

\section{Measures}

\section{E-Cigarettes:}

In phase one, participants were presented with two e-cigarettes: a first generation E-30 rechargeable cartomiser device purchased from E-Lites, chosen because of its clear visual resemblance to a tobacco cigarette (cigalike), and a second generation, stainless steel eGo-T purchased from Joyetech which resembled a silver fountain pen.

In phase two, the same eGo-T second generation device was used but the first generation rechargeable device was replaced with a disposable cigarette-like device purchased from Totally 
Wicked (the disposable device represents the simplest device on the market and requires no charging or changing of cartridges). $18 \mathrm{mg} / \mathrm{ml}$ nicotine strength, tobacco flavoured cartridges were used in both cases.

Questionnaires:

Cigarette Dependence was assessed using the Fagerström Test of Cigarette Dependence (FTCD) [28], a six-item questionnaire providing an overall dependence score ranging from 0 (low dependence) to 10 (high dependence).

Craving and withdrawal symptoms (WS) were measured using the Mood and Physical Symptoms Scale (MPSS) [29]. Dimensions include 'urge to smoke' right now, measured on a seven-point rating scale (scores range from 1 to 7: 'Not at all strong' to 'Extremely strong') and 'depressed mood', 'irritability', 'anxiety', 'restlessness', 'hunger' and 'inability to concentrate', each measured using a five-point rating scale (scores range from 1 to 5: 'Not at all' to 'Extremely'). Individual item scores are summed to provide an overall total WS score (possible range: $6-30$ ).

The main reason for first versus second generation e-cigarette choice was gathered via the single question: 'Which factor played the most important role in choosing the e-cigarette?' with the following options: 'Because it resembles a conventional cigarette', 'Because it does not resemble a conventional cigarette', 'Because it is stylish', 'Because I thought it would be good for delivering nicotine'. Participants could select only one option.

Subjective effects relating to e-cigarette use were each rated on a three-point scale: satisfaction (not at all, fairly, very), hit (no, partly, yes), whether the e-cigarette felt like smoking (not at all, partly, yes) and whether participants would use the e-cigarette in a quit attempt (no, maybe, yes). For analytical simplicity, responses were then re-coded into two categories (i.e. no vs. yes with the two positive categories combined). 
Socio-demographic information (including age, gender, ethnicity, occupation and highest qualification) and further data on smoking habits (e.g. cigarettes per day; CPD) and e-cigarette awareness and use were also recorded.

\section{Procedure}

\section{Phase 1:}

Following informed consent and a carbon monoxide (CO) breath test, participants completed the baseline socio-demographic, smoking-related, urge to smoke and WS questionnaires. Participants were then presented with two e-cigarettes, a first-generation cartomiser device which resembled a cigarette in shape, size and colour (cigalike), and a second generation eGo device (counterbalanced for left vs. right positioning). They were asked: 'If you were to try one of these e-cigarettes today, which one would you choose?' After indicating their choice, participants then completed a questionnaire explaining their choice.

\section{Phase 2:}

Participants were then randomly allocated (via coin toss) to either a first generation cigalike or second generation (eGo) e-cigarette group (regardless of choice in phase 1). A new disposable device was used for each participant in the first generation group and mouth-pieces/cartridges were replaced and re-filled for each participant in the second generation group. Instructions were given to participants on how to use the e-cigarette (i.e. push and hold down button to activate, whilst drawing on the ecigarette). Participants were also instructed to start and stop puffing only upon the researcher's verbal signal. Participants were instructed to take ten puffs each of three-second duration with a thirtysecond inter-puff interval (IPI). The original intention was to use a longer four second puff duration 
(as recommended by [30]), however, during a pilot study it became evident that the four-second puff duration was too long for the cigalike device, producing over-heating and coughing. Consequently, puff length was reduced to three seconds for both conditions. After 10 minutes, participants again rated their urge to smoke and WS and completed the subjective effects questionnaire. Participants were then debriefed and given a disposable e-cigarette in compensation for their time. The study was fully approved by the University of East London's ethics committee.

\section{Statistical Analysis}

For phase 1, logistic regression (backwards likelihood ratio method) was used to generate odds ratios (OR) for selecting the first generation cigalike device associated with each of the predictor variables i) gender, ii) cigarette dependence (as measured by the FTCD), iii) previous e-cigarette use (any vs. no use) and age. For phase 2, multiple regression (backwards likelihood ratio method) was used to assess the effect of e-cigarette device ( $1^{\text {st }} v s 2^{\text {nd }}$ generation) on the dependent variables i) urge to smoke and ii) MPSS scores. Baseline urge to smoke/MPSS scores, gender, prior e-cigarette use and preference for first vs. second generation device (taken from phase 1 of the study) were entered as covariates.

Subjective effects (satisfaction, hit, felt like smoking and would use to quit smoking) were subjected to $2 \times 2$ (yes vs. no) chi square tests. An alpha value of $P<0.05$ was accepted as cut off for statistical significance.

\section{RESULTS}

\section{Phase 1}

Equal numbers of participants selected the first $(\mathrm{N}=48 ; 49.5 \%)$ versus the second $(\mathrm{N}=49 ; 50.5 \%)$ generation device. Evaluation of reasons given for choice confirmed that most of those who chose 
the cigalike device did so because it resembled a conventional cigarette (83\%). Other reasons were, 'because it is stylish' (8\%) and 'because I thought it would be good for delivering nicotine' (8\%). Reasons for selecting the second generation device were: 'it does not resemble a conventional cigarette' (45\%), 'it is stylish' (45\%), 'I thought it would be good for delivering nicotine (6\%) and 'other' (4\%).

The four predictor variables (gender, previous e-cigarette use, cigarette dependence and age) collectively explained $11 \%$ of the variance in e-cigarette choice in the initial model $\left(\chi^{2}=11.13, \mathrm{df}=8\right.$, $P=0.19 ;$ Nagelkerke pseudo $R^{2}=0.06$ ). Cigarette dependence was the only variable retained in the final model which accounted for $14.67 \%$ of the variance in e-cigarette choice (and was statistically better than the previous model: $\chi^{2}=14.67, \mathrm{df}=5, \mathrm{P}=0.01$; Nagelkerke pseudo $\mathrm{R}^{2}=0.04$ ) although FTCD was not a statistically significant predictor of e-cigarette choice (see Table 3).

\section{Phase 2}

For urge to smoke, the initial model with all five variables (e-cigarette device, baseline urge to smoke gender, prior e-cigarette use and phase 1 device preference) collectively accounted for $21.9 \%$ of the variance in urge to smoke following e-cigarette use $\left(\mathrm{F}_{5,91}=5.12, \mathrm{P}<0.001\right)$. E-cigarette device however, did not emerge as a significant predictor and the final model retained baseline urge to smoke only, accounting for $17.6 \%$ of the variance $\left(F_{1,95}=20.32, P<0.001\right)$. See Table 3 .

Similarly for WS, the initial model (e-cigarette device, baseline WS, gender, prior e-cigarette use and phase 1 device preference) significantly predicted WS following e-cigarette use $\left(F_{5,88}=11.14, P<\right.$ 0.001 ), accounting for $38.8 \%$ of the variance in WS. Again, e-cigarette device was not a statistically significant predictor and only baseline WS was retained in the final model $(F=56.99, P<0.001)$ accounting for $38.3 \%$ of the variance. See Table 4 .

In relation to subjective effects, compared to those using the first generation device, significantly more 
participants using the second generation device stated that the e-cigarette was satisfying $\left(\chi^{2}(1)=\right.$ $12.10, P=0.001)$, although there was no significant difference between groups for ratings of hit $\left(\chi^{2}(1)\right.$ $=2.18, \mathrm{P}=0.14)$. Those in the second generation group were also more likely to state that they would use the e-cigarette in a cessation attempt $\left(\chi^{2}(1)=5.53, P=0.02\right)$ and that the e-cigarette 'felt like smoking', although the latter did not reach statistical significance $\left(\chi^{2}(1)=3.16, P=0.08\right)$. See Table 4 . The groups did not differ on any other demographic or smoking related variable (Table 4).

\section{DISCUSSION}

This is the first study to examine e-cigarette choice, and to directly compare a first versus second generation device on urge to smoke, WS and subjective effects, in e-cigarette-inexperienced smokers. Half of regular smokers chose a first generation (cigalike) rather than a second generation device but none of the independent variables: gender, prior e-cigarette use, cigarette dependence or age, predicted device choice. First and second generation devices were equally effective in reducing urge to smoke and WS, although the latter was rated as more satisfying, and more likely to be used in a quit attempt.

When presented alongside a second generation eGo device, half of all regular smokers in this sample selected the first generation, cigalike device in phase 1 . The majority (83\%) stated the reason was its resemblance to a tobacco cigarette, indicating that for many people, visual similarity to a cigarette is an important determinant of initial e-cigarette device selection. Cigarette related cues such as visual appearance, sight/smell of smoke, or manipulation of a cigarette in the hand, over the course of a smoker's history, are repeatedly paired with the primary reinforcer, nicotine. Via this process of classical conditioning, such cues can become powerful secondary reinforcers, capable of providing 
some pleasure and alleviation of craving and WS themselves [31] which may explain some smoker's preference for a cigarette-like device. By contrast, almost half (45\%) of those selecting the second generation device did so because it did not resemble a cigarette. Although we did not probe further, this may be because it cannot be confused with a conventional cigarette by observers who disapprove of smoking. Alternatively, it may be because cigarette related cues can also act as conditioned stimuli [32], increasing craving [33] and the probability of smoking [34]. Cigarette-like cues clearly have different meanings for different individuals. Although we did not measure the importance of selfrated smoking-related cues here, elsewhere, higher quit rates have been observed among smokers using a cigarette-shaped non-nicotine inhalator only in those scoring high on the behavioural (nonnicotine) aspects of smoking [35].

None of the predictor variables: gender, prior e-cigarette use, cigarette dependence or age, were significant predictors of e-cigarette choice. We have previously reported, in a sample of 1347 regular e-cigarette users, that females were more likely to use first, and males to use second generation devices [23] although this was not reflected in the choices made by smokers here. Nevertheless, the previous study was based on actual use rather than visual appearance alone, as in the current study. Given the evidence that many regular users move on from first to second or third generation devices $[23,25,36]$ we also predicted that those who had some experience of using an e-cigarette in the past would be more likely to opt for a second generation device. That prior e-cigarette use was not a significant predictor here may reflect the fact that most users (82\%) had previously used an e-cigarette on fewer than five occasions.

In phase 2, only baseline urge/WS predicted the decline in urge to smoke and WS following e-cigarette use; the first and second generation devices were equally effective, and this effect was independent of prior e-cigarette use, device preference and gender. No other studies have directly compared first 
versus second generation devices in e-cigarette-inexperienced smokers, although Farsalinos and colleagues [15] have reported a greater reduction in e-cigarette craving and WS as well as higher blood nicotine levels in experienced users using a third, compared with a first generation device. The equivalency between devices in terms of alleviating urge to smoke and WS here, may reflect effective nicotine delivery in this product, its ability to replace some of the visual secondary reinforcing effects of smoking (by virtue of its resemblance to a cigarette) or both. Although one cannot distinguish between these possibilities, in support of the former, the first generation disposable e-cigarette from Totally Wicked selected here, has subsequently been associated with very good nicotine release to vapour compared with similar devices [37]. Thus whilst first generation devices are clearly capable of alleviating WS to a level commensurate with second generation devices, these findings cannot be generalised to the hundreds of other e-cigarettes on the market.

Despite comparable efficacy for the alleviation of urge to smoke and WS, more participants in the second generation group rated the device as satisfying, and perhaps consequently, stated that they would be more likely to use it in a quit attempt. By contrast, there was no difference between groups for subjective experience of hit. Examination of further comments provided by participants reveals that the second generation device was generally described as 'smoother' and the first generation device as 'harsher on the throat'. This might account for the higher levels of satisfaction and likelihood of use for quitting among those using the former.

There are a number of study limitations, most notably, the young, predominantly student sample with low cigarette dependence (mean FTCD 2.7); it is possible that, with more highly dependent smokers, differences between groups may emerge. Secondly, the smokers tested were only one-hour abstinent and therefore may not have been experiencing strong urges to smoke which may have reduced the magnitude of any reduction in urges/WS following e-cigarette use. Nevertheless, the mean baseline 
urge to smoke score (3.71, range: $1-7)$ is comparable with that observed in a sample of 145 smokers abstinent for $10-12$ hours ( $M=3.96$, range: $1-7 ;$ [32]) and was sufficiently high to produce a significant reduction following e-cigarette use. Finally, subjective measures were taken 10 minutes after 10 puffs on the e-cigarette. Whether comparable reduction in urge to smoke/WS continue over a longer time period remains unclear. At this time point (10 mins after 10 puffs), although measurable nicotine levels from the e-cigarette will have reached the blood [13], blood nicotine levels are still likely to be rising and it may be that significant differences between groups might emerge after 20/30 minutes [21].

Although replication in a more highly dependent sample of abstinent smokers with a longer follow up time after e-cigarette use is essential, we can tentatively conclude that: i) cigarette-like appearance is important for many smokers when choosing an e-cigarette device although individual factors predicting choice remain unclear; ii) first generation cigalike devices have the ability to be as effective as second generation devices for reducing cigarette urges and WS; iii) second generation devices may be more satisfying to use which may explain why more people report successfully quitting with them [25]. Although there is concern that first generation cigalike products in particular may re-normalise smoking, they clearly appeal to many smokers and compare favourably to second generation devices for craving/WS alleviation at least in the short term. Whether this effect is maintained over a longer term quit attempt by comparison with later generation devices remains to be determined.

\section{REFERENCES}


1. Goniewicz ML, Knysak J, Gawron M, Kosmider L, Sobczak A, Kurek J, et al. Levels of selected carcinogens and toxicants in vapour from electronic cigarettes. Tobacco control. 2014; 23 (2):133-9.

2. McAuley TR, Hopke P, Zhao J, Babaian S. Comparison of the effects of e-cigarette vapor and cigarette smoke on indoor air quality. Inhalation toxicology. 2012; 24 (12):850-7.

3. Schripp T, Markewitz D, Uhde E, Salthammer T. Does e-cigarette consumption cause passive vaping? Indoor Air. 2013; 23 (1):25-31.

4. Stimson, Gerry. New estimates double size of US e-cigarette market; increasing importance of refillable and modified devices. Nicotine Science and Policy. 2014-10-22.

URL:http://nicotinepolicy.net/gerry-stimson/1317-wells-fargo-march-2014. Accessed: 201410-22. (Archived by WebCite at http://www.webcitation.org/6TVxSsvvR)

5. ASH, Action on Smoking and Health. Use of electronic cigarettes in Great Britain. www.ash.org.uk. 2014-10-22. URL:http://www.ash.org.uk/files/documents/ASH_891.pdf. Accessed: 2014-10-22. (Archived by WebCite at http://www.webcitation.org/6TVxrpdGH)

6. King BA, Alam S, Promoff G, Arrazola R, Dube SR. Awareness and ever-use of electronic cigarettes among US adults, 2010-2011. Nicotine \& tobacco research. 2013; 15 (9):1623-7.

7. Hajek P, Foulds J, Houezec JL, Sweanor D, Yach D. Should e-cigarettes be regulated as a medicinal device? The lancet Respiratory medicine. 2013; 1 (6):429.

8. Sweanor $D$, Alcabes $P$, Drucker $E$. Tobacco harm reduction: how rational public policy could transform a pandemic. International Journal of Drug Policy. 2007; 18 (2):70-4.

9. Dutra LM, Glantz SA. Electronic cigarettes and conventional cigarette use among US adolescents: a cross-sectional study. JAMA pediatrics. 2014.

10. Grana R, Benowitz N, Glantz SA. E-Cigarettes A Scientific Review. Circulation. 2014; 129 (19):1972-86.

11. Bullen C, McRobbie H, Thornley S, Glover M, Lin R, Laugesen M. Effect of an electronic nicotine delivery device (e cigarette) on desire to smoke and withdrawal, user preferences and nicotine delivery: randomised cross-over trial. Tobacco control. 2010; 19 (2):98-103.

12. Vansickel AR, Cobb CO, Weaver MF, Eissenberg TE. A clinical laboratory model for evaluating the acute effects of electronic "cigarettes": nicotine delivery profile and cardiovascular and subjective effects. Cancer Epidemiology Biomarkers \& Prevention. 2010; 19 (8):1945-53.

13. Dawkins L, Corcoran O. Acute electronic cigarette use: nicotine delivery and subjective effects in regular users. Psychopharmacology. 2014; 231 (2):401-7.

14. Vansickel AR, Eissenberg T. Electronic cigarettes: effective nicotine delivery after acute administration. Nicotine \& Tobacco Research. 2013; 15 (1):267-70. 
15. Farsalinos KE, Spyrou A, Tsimopoulou K, Stefopoulos C, Romagna G, Voudris V. Nicotine absorption from electronic cigarette use: comparison between first and new-generation devices. Scientific reports. 2014; 4.

16. Parrott AC, Craig D. Psychological functions served by nicotine chewing gum. Addictive behaviors. 1995; 20 (3):271-8.

17. Perkins KA, Karelitz JL, Conklin CA, Sayette MA, Giedgowd GE. Acute negative affect relief from smoking depends on the affect situation and measure but not on nicotine. Biological psychiatry. 2010; 67 (8):707-14.

18. Barrett SP. The effects of nicotine, denicotinized tobacco, and nicotine-containing tobacco on cigarette craving, withdrawal, and self-administration in male and female smokers. Behavioural pharmacology. 2010; 21 (2):144-52.

19. Rose JE, Salley A, Behm FM, Bates JE, Westman EC. Reinforcing effects of nicotine and nonnicotine components of cigarette smoke. Psychopharmacology. 2010; 210 (1):1-12.

20. Dawkins L. Why is it so hard to quit smoking? The Psychologist. 2013; 26 (5):332-5. PubMed PMID: 2013-30215-002.

21. Dawkins L, Turner J, Hasna S, Soar K. The electronic-cigarette: Effects on desire to smoke, withdrawal symptoms and cognition. Addictive Behaviors. 2012; 37 (8):970-3. PubMed PMID: 75355793.

22. Perkins KA, Donny E, Caggiula AR. Sex differences in nicotine effects and self-administration: review of human and animal evidence. Nicotine \& Tobacco Research. 1999; 1 (4):301. PubMed PMID: 6060844

23. Dawkins L, Turner J, Roberts A, Soar K. 'Vaping' profiles and preferences: An online survey of electronic cigarette users. Addiction. 2013; 108 (6):1115-25. PubMed PMID: 2013-16822018.

24. Etter J-F, Bullen C. Electronic cigarette: users profile, utilization, satisfaction and perceived efficacy. Addiction. 2011; 106 (11):2017-28. PubMed PMID: 66324657.

25. Farsalinos KE, Romagna G, Tsiapras D, Kyrzopoulos S, Voudris V. Evaluating nicotine levels selection and patterns of electronic cigarette use in a group of "vapers" who had achieved complete substitution of smoking. Substance abuse: research and treatment. 2013; 7:139.

26. Dawkins L, Turner J, Crowe E. Nicotine derived from the electronic cigarette improves timebased prospective memory in abstinent smokers. Psychopharmacology. 2013; 227 (3):37784. PubMed PMID: 87609508

27. Tabachnick BG, Fidell LS. Using multivariate statistics (5th ed.). Boston, MA: Allyn \& Bacon/Pearson Education; 2007. 
28. Fagerström K. Determinants of tobacco use and renaming the FTND to the Fagerström Test for Cigarette Dependence. Nicotine \& Tobacco Research. 2012; 14 (1):75-8. PubMed PMID: 2011-30003-008.

29. West R, Hajek P. Evaluation of the mood and physical symptoms scale (MPSS) to assess cigarette withdrawal. Psychopharmacology. 2004; 177 (1/2):195-9. PubMed PMID: 15244922.

30. Farsalinos KE, Romagna G, Tsiapras D, Kyrzopoulos S, Voudris V. Evaluation of electronic cigarette use (vaping) topography and estimation of liquid consumption: implications for research protocol standards definition and for public health authorities' regulation. International journal of environmental research and public health. 2013; 10 (6):2500-14.

31. Barrett SP, Darredeau C. The acute effects of nicotine on the subjective and behavioural responses to denicotinized tobacco in dependent smokers. Behavioural Pharmacology. 2012; 23 (3):221-7. PubMed PMID: 2012-13375-001.

32. Balfour DJK. The neurobiology of tobacco dependence: A preclinical perspective on the role of the dopamine projections to the nucleus. Nicotine \& Tobacco Research. 2004; 6 (6):899912. PubMed PMID: 15610003.

33. Dawkins L, Powell JH, West R, Powell J, Pickering A. A double-blind placebo controlled experimental study of nicotine: I-effects on incentive motivation. Psychopharmacology. 2006; 189 (3):355-67. PubMed PMID: 23127474.

34. Payne TJ, Smith PO, Adams SG, Diefenbach L. Pretreatment cue reactivity predicts end-oftreatment smoking. Addictive Behaviors. 2006; 31 (4):702-10. PubMed PMID: 20261148.

35. Caponnetto P, Cibella F, Mancuso S, Campagna D, Arcidiacono G, Polosa R. Effect of a nicotine-free inhalator as part of a smoking-cessation programme. European Respiratory Journal. 2011; 38 (5):1005-11.

36. McQueen A, Tower S, Sumner W. Interviews with 'vapers': Implications for future research with electronic cigarettes. Nicotine \& Tobacco Research. 2011; 13 (9):860-7. PubMed PMID: 2011-20512-012.

37. Goniewicz ML, Hajek P, McRobbie H. Nicotine content of electronic cigarettes, its release in vapour and its consistency across batches: regulatory implications. Addiction. 2014; 109 (3):500-7. PubMed PMID: 94396882. 
TABLES:

Table 1: Predictors of first generation e-cigarette choice (backwards likelihood ratio method)

\begin{tabular}{lcccccccc}
\hline & B & SE & Wald & df & P & OR & \multicolumn{2}{c}{$95 \%$ Cl for OR } \\
& & & & & & & & \\
& & & & & & & & \\
& & & & & & & & \\
\hline Step 1 & -0.18 & 0.43 & 0.18 & 1 & 0.68 & 0.84 & 0.36 & 1.94 \\
Gender & 0.24 & 0.43 & 0.33 & 1 & 0.57 & 1.28 & 0.55 & 2.94 \\
Prior e-cig use & -0.15 & 0.10 & 2.18 & 1 & 0.14 & 0.86 & 0.70 & 1.05 \\
FTCD & -0.03 & 0.03 & 0.94 & 1 & 0.33 & 0.97 & 0.92 & 1.03 \\
Age & 0.13 & 1.30 & 0.009 & 1 & 0.92 & 1.13 & & \\
Constant & & & & & & & &
\end{tabular}

Step 2

$\begin{array}{lllllllll}\text { Prior e-cig use } & 0.26 & 0.42 & 0.37 & 1 & 0.54 & 1.29 & 0.56 & 2.97 \\ \text { FTCD } & -0.14 & 0.10 & 2.03 & 1 & 0.15 & 0.87 & 0.71 & 1.06 \\ \text { Age } & -0.03 & 0.03 & 0.94 & 1 & 0.33 & 0.97 & 0.92 & 1.03 \\ \text { Constant } & 0.91 & 0.71 & 1.61 & 1 & 0.20 & 2.48 & & \end{array}$

Step 3

$\begin{array}{lllllllll}\text { FTCD } & -0.15 & 0.10 & 2.32 & 1 & 0.13 & 0.86 & 0.71 & 1.04 \\ \text { Age } & -0.02 & 0.03 & 0.82 & 1 & 0.36 & 0.98 & 0.93 & 1.03 \\ \text { Constant } & 0.99 & 0.70 & 2.02 & 1 & 0.16 & 2.70 & & \end{array}$

Step 4

$\begin{array}{lllllllll}\text { FTCD } & -0.17 & 0.10 & 3.07 & 1 & 0.08 & 0.85 & 0.70 & 1.02 \\ \text { Constant } & 0.43 & 0.33 & 1.73 & 1 & 0.19 & 1.54 & & \end{array}$


Table 2: Predictors of urge to smoke following e-cigarette use (backwards likelihood ratio method)

\begin{tabular}{|c|c|c|c|c|c|c|c|}
\hline & \multirow[t]{2}{*}{ B } & \multirow[t]{2}{*}{ SE } & \multirow[t]{2}{*}{$\beta$} & \multirow[t]{2}{*}{$\mathbf{t}$} & \multirow[t]{2}{*}{$\mathbf{P}$} & \multicolumn{2}{|c|}{$95 \% \mathrm{Cl}$ for $\mathrm{B}$} \\
\hline & & & & & & Lower & Upper \\
\hline \multicolumn{8}{|l|}{ Step 1} \\
\hline E-cig device & 0.34 & 0.27 & 0.12 & 1.24 & 0.22 & -0.20 & 0.87 \\
\hline Baseline urge & 0.36 & 0.09 & 0.40 & 4.28 & 0.00 & 0.19 & 0.53 \\
\hline Gender & -0.34 & 0.27 & -0.12 & -1.27 & 0.21 & -0.87 & 0.19 \\
\hline Prior e-cig use & -0.34 & 0.27 & -0.12 & -1.25 & 0.22 & -0.88 & 0.20 \\
\hline Device preference & 0.16 & 0.27 & 0.06 & 0.59 & 0.56 & -0.38 & 0.70 \\
\hline Constant & 0.94 & 0.71 & & 1.31 & 0.19 & -0.48 & 2.35 \\
\hline
\end{tabular}

Step 2

$\begin{array}{lccccccc}\text { E-cig device } & 0.34 & 0.27 & 0.12 & 1.27 & 0.21 & -0.19 & 0.87 \\ \text { Baseline urge } & 0.35 & 0.08 & 0.40 & 4.26 & 0.00 & 0.19 & 0.52 \\ \text { Gender } & -0.32 & 0.27 & -0.11 & -1.22 & 0.23 & -0.85 & 0.20 \\ \text { Prior e-cig use } & -0.34 & 0.27 & -0.12 & -1.27 & 0.21 & -0.88 & 0.19 \\ \text { Constant } & 1.03 & 0.69 & & 1.48 & 1.41 & -0.35 & 2.40\end{array}$

Step 3

$\begin{array}{llllllll}\text { E-cig device } & 0.37 & 0.27 & 0.13 & 1.40 & 0.17 & -0.16 & 0.90 \\ \text { Baseline urge } & 0.36 & 0.83 & 0.40 & 4.31 & 0.00 & 0.19 & 0.53 \\ \text { Prior e-cig use } & -0.37 & 0.27 & -0.13 & -1.36 & 0.18 & -0.90 & 0.17 \\ \text { Constant } & 0.47 & 0.52 & & 0.90 & 0.37 & -0.57 & 1.51\end{array}$

\section{Step 4}

$\begin{array}{llllllll}\text { E-cig device } & 0.31 & 0.26 & 0.11 & 1.17 & 0.25 & -0.22 & 0.83 \\ \text { Baseline urge } & 0.37 & 0.83 & 0.42 & 4.46 & 0.00 & 0.21 & 0.54 \\ \text { Constant } & 0.32 & 0.51 & & 0.62 & 0.53 & -0.70 & 1.34\end{array}$

\section{Step 5}

$\begin{array}{llllllll}\text { Baseline urge } & 0.38 & 0.08 & 0.42 & 4.51 & 0.00 & 0.21 & 0.54 \\ \text { constant } & 0.77 & 0.34 & & 2.29 & 0.02 & 0.10 & 1.44\end{array}$


Table 3: Predictors of withdrawal symptoms (WS) following e-cigarette use (backwards likelihood ratio method)

\begin{tabular}{|c|c|c|c|c|c|c|c|}
\hline & \multirow[t]{2}{*}{ B } & \multirow[t]{2}{*}{ SE } & \multirow[t]{2}{*}{$\beta$} & \multirow[t]{2}{*}{$\mathbf{t}$} & \multirow[t]{2}{*}{$\mathbf{P}$} & \multicolumn{2}{|c|}{$95 \% \mathrm{Cl}$ for $\mathrm{B}$} \\
\hline & & & & & & Lower & Upper \\
\hline \multicolumn{8}{|l|}{ Step 1} \\
\hline E-cig device & -0.32 & 0.51 & -0.05 & -0.61 & 0.54 & -1.34 & 0.71 \\
\hline Baseline WS & 0.54 & 0.07 & 0.63 & 7.40 & 0.00 & 0.39 & 0.68 \\
\hline Gender & 0.17 & 0.52 & 0.03 & 0.32 & 0.75 & -0.86 & 1.19 \\
\hline Prior e-cig use & 0.01 & 0.52 & 0.01 & 0.01 & 0.99 & -1.02 & 1.03 \\
\hline Device preference & 0.22 & 0.51 & 0.04 & 0.44 & 0.66 & -0.79 & 1.24 \\
\hline Constant & 3.55 & 1.49 & & 2.38 & 0.02 & 0.59 & 6.52 \\
\hline
\end{tabular}

\section{Step 2}

$\begin{array}{llllllll}\text { E-cig device } & -0.31 & 0.50 & -0.05 & -0.32 & 0.53 & -1.31 & 0.69 \\ \text { Baseline WS } & 0.54 & 0.07 & 0.63 & 7.46 & 0.00 & 0.39 & 0.68 \\ \text { Gender } & 0.17 & 0.51 & 0.03 & 0.34 & 0.75 & -0.85 & 1.19 \\ \text { Device preference } & 0.22 & 0.51 & 0.34 & 0.44 & 0.66 & -0.79 & 1.23 \\ \text { Constant } & 3.55 & 1.48 & & 2.40 & 0.02 & 0.61 & 6.50\end{array}$

Step 3

$\begin{array}{llllllll}\text { E-cig device } & -0.33 & 0.50 & -0.06 & -0.67 & 0.51 & -1.32 & 0.66 \\ \text { Baseline WS } & 0.53 & 0.07 & 0.62 & 7.53 & 0.00 & 0.39 & 0.67 \\ \text { Device preference } & 0.24 & 0.50 & 0.04 & 0.47 & 0.64 & -0.76 & 1.24 \\ \text { Constant } & 3.87 & 1.12 & & 3.45 & 0.00 & 1.89 & 6.14\end{array}$

Step 4

$\begin{array}{llllllll}\text { E-cig device } & -0.33 & 0.50 & -0.05 & -0.66 & 0.51 & -1.31 & 0.66 \\ \text { Baseline WS } & 0.53 & 0.07 & 0.62 & 7.55 & 0.00 & 0.39 & 0.67 \\ \text { Constant } & 4.02 & 1.07 & & 3.75 & 0.00 & 1.89 & 6.14\end{array}$

Step 5

$\begin{array}{llllllll}\text { Baseline WS } & 0.53 & 0.07 & 0.62 & 7.55 & 0.00 & 0.39 & 0.67 \\ \text { constant } & 3.55 & 0.81 & & 4.41 & 0.00 & 1.96 & 5.15\end{array}$


Table 4: Smoking-related/demographic variables and positive subjective effects of the e-cigarette by condition (first vs. second generation device)

\begin{tabular}{|c|c|c|c|c|}
\hline & $\begin{array}{c}\mathbf{1}^{\text {st }} \text { generation } \\
\text { (cigalike) } \\
\mathrm{N}=46\end{array}$ & $\begin{array}{c}2^{\text {nd }} \text { generation } \\
\text { (e-Go) } \\
\mathbf{N}=\mathbf{5 0}\end{array}$ & & \\
\hline & $\mathbf{N}(\%)$ & $\mathbf{N}(\%)$ & $x^{2}$ & $\mathbf{P}$ \\
\hline Gender: female & $28(60)$ & $25(50)$ & 0.90 & 0.34 \\
\hline Occupation: student & $38(81)$ & $41(82)$ & 0.02 & 0.88 \\
\hline Education: A-level + & $42(89)$ & $44(88)$ & 1.66 & 0.65 \\
\hline Ethnicity: European & $26(53)$ & $32(64)$ & 2.61 & 0.76 \\
\hline Prior e-cig use: Yes & $22(47)$ & $32(64)$ & 2.90 & 0.09 \\
\hline Satisfying: Yes & $32(67)$ & $49(94)$ & 12.32 & 0.00 \\
\hline Hit: Yes & $36(75)$ & $46(88)$ & 3.06 & 0.08 \\
\hline Use to Quit: Yes & $38(79)$ & $50(96)$ & 6.82 & 0.01 \\
\hline \multirow[t]{2}{*}{ Felt like smoking: yes } & $37(77)$ & $47(90)$ & 3.29 & 0.07 \\
\hline & Mean (SD) & Mean (SD) & $\mathbf{t}$ & $\mathbf{P}$ \\
\hline Age & $25(7.45)$ & $26(9.21)$ & -0.57 & 0.57 \\
\hline CO level & $9.37(5.30)$ & $10.54(5.11)$ & -1.09 & 0.28 \\
\hline Years smoked & $7.91(7.30)$ & $9.44(8.72)$ & -0.93 & 0.35 \\
\hline CPD & $10.30(5.23)$ & $11.32(3.69)$ & -1.13 & 0.26 \\
\hline FTCD & $2.62(2.46)$ & $2.80(1.95)$ & -0.40 & 0.69 \\
\hline
\end{tabular}

